\title{
Sharing bad news of a lung cancer diagnosis: Understanding through Communication Privacy Management Theory.
}

\begin{abstract}
Objective: To understand the process of information disclosure and privacy as patients share their news of lung cancer with significant others.

Methods: Twenty patients with lung cancer and 17 family members/friends accompanying them at diagnosis-giving completed either individual or dyad semi-structured interviews.

Initial thematic analysis, then Petronio's Communication Privacy Management theory was used to inform interpretation.

Results: Patients described a sense of ownership of the news of their cancer and sought control of how, when and with whom it was shared. Family members expressed a need to follow the patients' rules in sharing this news which limited their own support systems. Patients and family members had to live within the relational communication boundaries in order to maintain their trusting relationship and avoid potential disruptions.

Conclusion: Patients as individuals are strongly interlinked with significant others which impacts on their experience of disclosing private information. This shapes their psychological processes and outcomes impacting on their illness experience. This should be considered when developing interventions to support patients with sharing bad news.
\end{abstract}

\section{Keywords:}

Cancer, oncology, communication, qualitative research, disclosure. 


\section{Background}

Communication in lung cancer diagnosis-giving impacts very many people: there were nearly

1.83 million new cases of lung cancer worldwide in 2012 [1]. It is the second most common cancer in the UK: daily around 120 people were diagnosed in 2012 [1]. Patients often present at an advanced stage when there are fewer treatment options [2]. As a result of late diagnosis

disease progression is rapid, increasing symptom burden and distress compared to other cancers [3] and with greater psychological health challenges [4].

In the past two decades there has been a plethora of research on how clinicians break bad news to patients [5-7], leading to publication of guidelines and recommendations for breaking bad news [8]. However we found little research on the subsequent process, which we have termed Sharing Bad News, when patients go home and relate news they have received about their diagnosis to adult family, friends and work colleagues and how they can be supported with thisprocess.

Within the adult population, the absence of research into how families and friends communicate about cancer has been noted [9]. We identified studies that focussed on communication in couples [10-13] and with wider family [14-15], however we found none addressed the specific process of sharing bad news with significant others. Nor are the practicalities of sharing bad news evident in the literature on disclosure of a cancer diagnosis, which focuses on issues such as the meanings that the disclosure conversations reveal [16], needs at diagnosis and reactions perceived in others [17], or on the decision to 'disclose' as opposed to how news is shared [18]. However, telling family and friends about their

diagnosis is reported as one of the hardest aspects of having cancer [18].

Thus in summary, despite an extensive literature search of clinical research as well as literature on spousal and family communication in cancer we found a dearth of studies on how patients with cancer tell adult significant others about their diagnosis ie, on sharing bad news.

This article reports a component of a health services research study which investigated patients' experiences of sharing news of a lung cancer diagnosis in order to develop an intervention for healthcare professionals to support patient with sharing bad news [19]. To further inform intervention development, we also examined the communication process

taking place between patients and those with whom they shared bad news, using the context of Communication Privacy Management (CPM). Within health, questions of privacy are becoming more pertinent with medical advances [20], as people struggle with how to share

information or with self-disclosure. CPM provides a comprehensive view of sharing private information, considering not only how individuals make decisions about how much information about themselves to share with others but also how much to withhold [21]. (Box 1 below describes CPM). The objective of this article is to understand the process of disclosure and privacy when sharing news of lung cancer.

[insert box 1 here] 


\section{Methods}

A qualitative research design used interviews with patients with a lung cancer diagnosis and family members/friends accompanying them to diagnosis-giving consultations.

The study received ethics approval from NRES Committee East of England-Hertfordshire (Reference Number 11/EE/0440). Written informed consent was obtained from all participants.

\section{Recruitment and sample}

The study was conducted in an East of England Regional Thoracic Oncology Unit. Patients were recruited from lung cancer clinics (February-October 2012). Inclusion criteria were: a diagnosis of lung cancer, not eligible for potentially curative surgery, $\geq 18$ years of age and

able to give informed consent. Patients from all palliative pathways were included: palliative chemotherapy, palliative radiotherapy and supportive care.

Patients attending treatment and follow-up clinics were identified by clinical nurse specialists (CNSs), who gave eligible participants a recruitment pack containing an invitation letter, information leaflet, a reply form and freepost envelope to reply directly to the research team.

The researcher then contacted patients to answer any questions and make an appointment for interview. Patients were asked if they had an accompanying person (AP) at diagnosis or oncology clinic consultations and whether they would be willing for the researchers to contact them. If the patient agreed, a similar recruitment pack was sent to the AP. Non responding patients were followed up by CNSs within four weeks to enquire whether they needed any further information. Due to ethical requirements the research team were not allowed access to any background information of non-responders.

\section{Participants}

Twenty patients and 17 accompanying persons (total $\mathrm{N}=37$ ) took part in interviews. Nineteen patients had non-curable lung cancer and one patient was having a potentially curative therapy (self-reported and verified by attending clinician). One patient had two APs who took part, two patients did not have an AP, and two had a spouse who could not participate in the study due to time constraints. One patient had a daughter as an AP, two patients had their sons, one had a sister and work colleague, and 12 had their spouse participate in the study as an AP. The median age of the patient sample was 67.5 years; (14

Male, 6 Female). Age was not recorded for the APs; (12 Female, 5 Male).

\section{Data collection}

Open semi-structured interviews were conducted in the participant's place of choice, usually their home by two of the authors (GE/NN), both experienced in conducting interviews of a sensitive nature. The topic guide was informed by pilot work with users who had experience of sharing bad news and with clinicians. A conversational approach was taken in interviews, allowing participants to respond in their own words to broad questions about their experiences of (1) receiving diagnosis news (including the context in which they received the news and who accompanied them) (2) any information and support received from healthcare professionals at this stage, (3) the process and experience of sharing their news with 
family/friends (how they went about it, concerns or any difficulties they had) and (4) how healthcare professionals could improve this process for them. Prompts were used when necessary to facilitate participants' talk. Interviews lasted on average 45 minutes. Participants were offered a break if they felt they needed one. The family members' interviews had a similar structure and content as that of the patients, although the focus was their experience of their involvement in the process as an accompanying person.

\section{Analysis}

Interviews were fully transcribed, transcripts checked for accuracy and anonymised and then imported into Nvivo 9, a software programme which facilitates data management and Framework analysis [28]. Data analysis was conducted by two of the authors (NN/GE). The focus of this initial stage of analysis was issues related to intervention development. The process involved reading and re-reading four initial interviews to identify key issues. These were reviewed, discussed and then a coding framework devised for entering interviews on to Nvivo. Transcripts of the first five patients and APs were read and summarised on the framework. This allowed it to be reviewed and adjusted to ensure it captured all the issues discussed in interviews before entering the remaining interviews. Thereafter, codes were discussed between the researchers followed by the categorisation and conceptualisation process reducing the data into meaningful themes following thematic analysis [29]. The point

of theoretical saturation was confirmed when no new conceptual insights emerged from the constant comparison of the new codes to previously coded data. Notes and memos were written throughout the analysis. Initial findings were discussed with members of the Monitoring and Advisory Group and feedback incorporated into the analysis.

A supplementary analysis was then undertaken to address the objective of this article: further understanding of the process of information disclosure. Interviews were re-examined using the framework of CPM, in the manner described by Sandelowski [30], using it to provide a comparative context or an organizational framework for data interpretation. CPM has been

successfully used to interpret and translate communication research within the health context for various health conditions including HIV/AIDS, cancer and in end of life care [31-32]. The approach taken here uses the theory as a 'scaffold' as described in Morse and Mitcham [33], enabling further exploration of the communication process in sharing bad news.

\section{Results}

The communication process was examined from the standpoint that the way a person experiences their health or illness involves other people within their social context. This interconnectedness with others or 'relational being' impacts the way an individual expresses themselves and their experience of everyday life. Thus in this paper we explore the notion of 'relational being' in sharing news of cancer with adult significant others.

The way individuals shared news varied across the sample and differed depending on what stage of treatment the patient was in at the time of the interview. Patients reported a sense of 
ownership of the news whilst the APs talked about how their involvement in sharing the news depended on the patient's views and wishes. The findings are presented under three main themes; 1) "It's my illness"; 2) "I just follow her lead"; and 3) the sake of relational harmony.

In providing illustrative quotations, participants are identified by their research code (first letter P (patient), AP (accompanying persons). Original IDs have been recoded to ensure anonymity. Ellipses (....) indicate omitted text.

\section{1) 'It's my illness'}

Patients felt that since they were the ones with the physical illness, the information about their diagnosis was their own. They consistently described any information around the illness as belonging to them and needed to have full control of what happened to it.

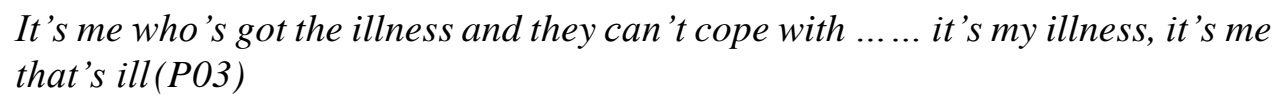

Patients expressed how they felt they had the right to decide with whom to share, how and

when to do so. They wanted to decide the appropriate time to share the news: a time that was convenient for them and done in the way they wanted. They described having the prerogative to deal with the information in the way they saw fit.

I love my mum ...... I was dreading telling her, but I told her why and how I wanted it to be and positive, and that's just the way I have been with everybody. (P19)

Patients made decisions on what information they wanted to share and what they chose to withhold.

I told them that I will probably be on chemotherapy but I didn't tell them what the prognosis was. [Referring to husband] I would rather he didn't know. I'll tell him when it's, you know, when it's time to tell him, I'll tell him (P01)

While accepting the need to share the news, participants valued being able to control the news and being the gatekeeper of the privacy boundary.

But then when we got back to my place I sent an email to about eight or ten close friends and family... And then said but for tonight I'm closing down communications...I didn't actually want people to start phoning me that very night.... (P20)

\section{2) 'I just follow her lead'.}

This theme was identified as a significant challenge for some APs. Many conveyed how they put their own feelings and emotions aside in following the patient's lead. Trying as much as possible to accommodate the patient's feelings and desires, thus most of their actions were 
based on the patients' needs. They shared the information according to the patient's instructions regardless of whether that was a mutual view.

Exactly how mum wants me to go about it, so whatever story she wants to tell that's the story I'll tell not that it's a lie or anything. (AP19)

APs described being guided by the patient in many aspects associated with the illness information. They felt their needs were trivial and their responsibility was to do whatever the patient wanted with regards to their news.

I know I have to say (to patient) now that I am staying here just tell me the things I should or shouldn't do, you've got tell me. (AP20)

3) The sake of relational harmony.

Patients needed to rely on those to whom they disclosed their news. This meant negotiating relational boundaries within which to deal with the information. Personal privacy becomes shared mutual privacy with both individuals having a responsibility for protecting the information and development of boundary rules. This had an impact on how both the patient as the owner of the news and AP as a co-owner experienced the illness.

Difficulties were expressed in negotiating boundaries involving decisions on who else APs could share the news with. Those who had not negotiated boundaries during the disclosure of the information had to later seek permission from patients to avoid boundary turbulence.

I had just not shared it initially, then I asked her and she said 'well, perhaps not yet', something like that. (AP21)

The experience of patients and APs as co-owners of the shared news developed reciprocal responsibility which meant negotiating privacy rules to avoid boundary turbulence. In order

to have efficient regulation of the information and avoid unwanted exposure through possible misunderstandings, patients often had to set the boundaries by telling APs situations when they could share the information.

[What patient said to family member] 'Don't say anything to anyone till I'm ready.' ..... But if they asked ... if anybody asked them outside how I was, I gave them permission then that they can just say. (P14)

Although in this study, there were no clear incidents of boundary turbulence reported, one participant described a situation where they felt the co-owner had failed to follow the explicit rules to control the information. The patient's narrative describes how this violation of the boundary rules had an undesirable effect and how it made him feel.

I told him, I said "Whatever you say don't tell anyone" but of course he did, he mentioned it to one person ... which I was, I was just about to break down.(P12) 


\section{Discussion}

\section{Overview of findings}

The findings of this study show how CPM principles apply to privacy management in sharing news of a diagnosis of lung cancer since 1) patients believe they own private information about their diagnosis, 2) believe they should control the flow of that information, 3) they decide who can have access to the information, 4) believe that whoever has been given access

to the information will abide by the privacy management rules created, and finally 5) accompanying persons are aware that turbulence may occur if the privacy management rules are broken.

\section{Relationship to previous literature}

Our findings add to the growing evidence that CPM can be used in developing translational research [24, 34-36] as it is a useful theoretical framework in understanding privacy management within a communication perspective [37]. Besides the physical and psychological impact of their illness, patients have to contend with issues of privacy

boundaries by negotiating rules to gain control while coming to terms with the news. This is evidenced by patients' attempts to contain the news thus regulating the degree of accessibility to the information [25]. These findings are consistent with those of Benson and colleagues [38] who found that cancer patients expressed a notion of ownership of information on their diagnosis or prognosis. Although in a way this ownership can increase the sense of autonomy [22], it can also be a burden. There is a responsibility attached to the information and patients feel accountable for how this information is handled both by them and by the recipient.

Family caregivers of cancer patients provide emotional and informational support amongst other roles. This can be a stressful time for individuals in this position with more than $50 \%$ reporting significant distress [39]. Accompanying persons were reluctant to share their

emotions or the impact of the news with the patient. This finding is in agreement with Badr and colleagues who found that caregivers struggle with discussing aspects of the patients' illness especially the prognosis and their own emotions [10]. As the theme of privacy rules and co-ownership has illustrated, the patient and accompanying person are both involved in the effort of maintaining the boundary and thus relational privacy is an important issue in privacy management.

The safety or security of the shared information is determined by the interdependent relationship that the owner and co-owner have. The AP had partial responsibility for the

information and had to either withhold it from other people or share it, according to the patient's wishes. They indicated that this was emotionally challenging for them as they did not have control of the news and tried to avoid boundary turbulence. This can occasionally leave their emotional needs neglected as they respect the 'collective privacy boundary' rules

by following the patient's lead. Although there was an awareness of boundary turbulence, there was limited evidence of its occurrence in this study. A possible explanation for this may be the sensitive and emotive context of the topic: that of a terminal diagnosis. According to $\mathrm{CPM}$, context is one of the five factors that influence privacy management and disclosure 
[21]. Another possible explanation, evidenced by the effort that APs made to avoid turbulence, is the risk-benefit ratios. Research has shown that when the risk level of information is high, efforts to maintain the boundary increase [40] and this may apply in the context of a terminal illness.

As the results show, the patient's experience of sharing their news is within a relational paradigm which involves and is interconnected with the AP and significant others. These results further support previous research that points to the importance of the relational model

within healthcare [25]. The relational model acknowledges the role that significant others play in the patients' health and wellbeing.

\section{Study limitations}

As a qualitative study with a modest sample size, generalizability to the wider population is not a goal. However our experience of disseminating study findings has been not only recognition of the value of identifying the process of sharing bad news by clinician audiences, but also the usefulness of the theoretical explanations from this paper (a poster based on this paper was presented at the British Thoracic Oncology Group Conference,

2014).

A limitation, however, is that we do not know whether those taking part in the study were different from those who did not as we did not have access to non-responders' details. Due to the sample size some elements of patients' and family members' experiences may not have

been detected in our analyses although we believe theoretical saturation was reached. Feedback from dissemination audiences also indicated resonance with our study findings. Nevertheless participants from other cultures may experience sharing bad news differently due to their sociocultural background and cultural views of 'the self'.

The concept of turbulence was not identified in the data collected and this could be attributed to the analysis approach taken. However the strength of this scaffolding approach is the ability to move empirical data from being simply descriptive to an explanation of phenomenon and also avoids force fitting theoretical formulations to data.

\section{Research and clinical implications}

Despite these limitations, this study shows how theoretical perspectives can be used to interpret empirical research findings. It also adds to the literature that supports CPM as a theory in communicating private information. Our findings suggest that the impact of sharing

news of lung cancer is a major challenge for patients. Health care professionals need to be aware that sharing this bad news is difficult for patients and they may benefit from additional support. Although patients had not requested support in sharing news about their diagnosis or prognosis, none expressed reluctance in their interviews about receiving information or being signposted to sources of support. Several described how this would have been a valuable form of support for them as it is a difficult aspect of their illness experience. The challenge for clinical practice, therefore, is to develop an intervention that healthcare professionals can proactively use to support patients and their families in this difficult process. 


\section{Acknowledgments}

This Sharing Bad News study benefited greatly from the support and advice of our

Monitoring and Advisory Group (MAG): Sue Bailey, Dr David Gilligan, Dr John Benson,

Mandy Williams and Professor Jane Seymour. We are grateful for the advice of Eve Godoy and Hilary Tunnicliffe who were PPI advisors to the study and also members of the MAG. We wish to express gratitude to Professor Janice Morse, College Of Nursing, University of

Utah for advice and guidance on methodology aspects of this article.

We also express our gratitude to all study participants for their contributions to this study,

This project was funded by Dimbleby Cancer Care Research Fund.

An abstract based on this study has been published:

Ngwenya NB, Farquhar M, Benson J, Gilligan D, Bailey S, Seymour J, Ewing G. Sharing Bad News: Understanding the communication processes of a lung cancer diagnosis. Lung Cancer 2014; 83: S38. 


\section{References}

1. CRUK: Lung cancer statistics [ONLINE]. Available at http://www.cancerresearchuk.org/cancer-info/cancerstats/types/lung/Last accessed on $27 / 02 / 2015$

2. Liao YC, Liao WY, Shun SC, Yu CJ, Yang PC, Lai YH. Symptoms, psychological distress, and supportive care needs in lung cancer patients. Supportive Care in Cancer 2011; 19:17431751

3. Carlson LE, Waller A, Groff SL, Bultz BD. Screening for distress, the sixth vital sign, in lung cancer patients: effects on pain, fatigue, and common problem secondary outcomes of a randomized controlled trial. Psycho-Oncology 2013; 22:1880-1888

4. Kurita K, Garon EB, Stanton AL, Meyerowitz BE. Uncertainty and psychological adjustment in patients with lung cancer. Psycho-Oncology 2013; 22:1396-1401

5. Ptacek JT. Breaking bad news. A review of the literature. JAMA 1996; 276:496-502.

6. Fallowfield L, Jenkins V. Communicating sad, bad, and difficult news in medicine. Lancet 2004; 363:312-9.

7. Hack TF, Degner LF, Parker PA. The communication goals and needs of cancer patients: A review. Psycho-oncology 2005; 14:831-45.

8. Baile W, Buckman R, Lenzi R, Glober G, Beale EA, Kudelka APl. SPIKES - A six-step protocol for delivering bad news: application to the patient with cancer. Oncologist 2000, 5:302-11

9. Beach WA, Anderson JK. Communication and cancer? Part I: the noticeable absence of interactional research. Journal of Psychosocial Oncology 2003; 21(3):1-23.

10. Badr H, Taylor CL. Social constraints and spousal communication in lung cancer. Psychooncology 2006; 15(8):673-83.

11. Pistrang N, Barker C, Rutter C. Social support as conversation: analysing breast cancer patients' interactions with their partners. Soc Sci.Med 1997; 45(5):773-82.

12. Boehmer UE, Clark JA. Married couples' perspectives on prostate cancer diagnosis and treatment decision-making. Psycho-oncology 2001; 10(2):147-55.

13. Porter LS, Keefe FJ, Hurwitz H, Faber M. Disclosure between patients with gastrointestinal cancer and their spouses. Psycho-oncology 2005; 14(12):1030-42.

14. Raveis VH, Pretter S. Existential plight of adult daughters following their mother's breast cancer diagnosis. Psycho-oncology 2005; 14(1):49-60.

15. Zhang AY, Siminoff LA. Silence and cancer: why do families and patients fail to communicate? Health Communication 2003; 15(4):415-29. 
16. Beach WA. Between dad and son: initiating, delivering, and assimilating bad cancer news. Health Communication 2002; 14(3):271-98.

17. Kuczynski K. Life-threatening illness and the nature of social support: brief research report. Journal of Psychosocial Oncology 2008; 26(3):113-23.

18. Hilton S, Emslie C, Hunt K, Chapple A, Zeibland S. Disclosing a cancer diagnosis to friends and family: a gendered analysis of young men's and women's experiences. Qualitative Health Research 2009; 19(6):744-54.

19. Ewing G, Ngwenya M, Benson J, Gilligan D, Bailey S, Seymour J, Farquhar M. Sharing news of a lung cancer diagnosis with adult family members and friends: a qualitative study to inform a supportive intervention. Patient Education and Counselling (in press).

20. Jin SAA. "To disclose or not to disclose, that is the question": A structural equation modeling approach to communication privacy management in e-health. Computers in Human Behavior

2012; 28:69-77.

21. Petronio S: Boundaries of Privacy: Dialectics of Disclosure. Albany, New York: State University of New York; 2002.

22. Petronio S, Reierson J. Regulating the Privacy of Confidentialitv: Grasping the Complexities through Communication Privacy Management Theorv. In Uncertainty, Information Management, and Disclosure Decisions:Theories and Applications, Afifi TA, Afifi WA (Ed.). New York: Routledge; 2009:365-383.

23. Griffin E. Communication Privacy Management Theory by Sandra Petronio. In A First Look at Communication Theory. 8th edition McGraw-Hill; 2011:168-180.

24. Metzger MJ. Communication privacy management in electronic commerce. Journal of Computer-Mediated Communication 2007; 12: 335-361.

25. Petronio S, Kovach S. Managing privacy boundaries: Health providers' perceptions of resident care in Scottish nursing homes. Journal of Applied Communication Research 1997; 25:115131.

26. Petronio S, Sargent J, Andea L, Reganis P, Cichocki D. Family and friends as informal healthcare advocates. Journal of Social and Personal Relationships 2004; 21:33-52.

27. Baumeister RF, Leary MR. The Need to Belong - Desire for Interpersonal Attachments As A Fundamental Human-Motivation. Psychological Bulletin 1995;117:497-529.

28. Ritchie J, Spencer L, O’Connor W. Carrying out qualitative analysis. In: Ritchie J and Lewis J. Qualitative Research Practice, London: Sage 2003.

29. Saldana J. The Coding Manual for Qualitative Researchers. 3rd edition. CA: SAGE: Thousand Oaks; 2009. 
30. Sandelowski M. Theory Unmasked: the uses and guises of theory in qualitative research. Research in Nursing and Health. 1993: 16; 213-218.

31. Greene K, Derlega V, Yep G, Petronio S. Privacy and disclosure of HIV/AIDS in interpersonal relationships: A handbook for researchers and practitioners. Mahwah, NJ: Lawrence Erlbaum Associates; 2003.

32. Wittenberg-Lyles E, Goldsmith J, Ragan S, Sanchez - Reilly S. Dying with Comfort. Cresskill, NJ; Hampton Press Inc, 2010.

33. Morse JM and Mitcham C. Exploring Qualitatively derived Concepts: Inductive-Deductive Pitfalls. International Journal of Qualitative Methods (2002): 1(4); 28-35.

34. Petronio S, Reeder HM, Hecht ML, RosMendoza TM. Disclosure of sexual abuse by children and adolescents. Journal of Applied Communication Research 1996; 24:181-199.

35. Afifi TD. 'Feeling caught' in stepfamilies: Managing boundary turbulence through appropriate communication privacy rules. Journal of Social and Personal Relationships 2003; 20:729-755.

36. Lewis CC, Matheson DH, Brimacombe CAE. Factors Influencing Patient Disclosure to Physicians in Birth Control Clinics: An Application of the Communication Privacy Management Theory. Health Communication 2011; 26:502-511.

37. Petronio S. Translational research endeavors and the practices of communication privacy management. Journal of Applied Communication Research 2007; 35:218-222.

38. Benson J, Britten, N. Respecting the autonomy of cancer patients when talking with their families: qualitative analysis of semistructured interviews with patients. BMJ 1996; 313:729.

39. Ostlund U, Wennman-Larsen A, Persson C, Gustavsson P, Wengstrom Y. Mental health in significant others of patients dying from lung cancer. Psycho-Oncology 2010; 19:29-37.

40. Kennedy-Lightsey CD, Martin MM, Thompson M, Leezer Himes K, Zackery Clingerman B.

Communication Privacy Management Theory: Exploring Coordination and Ownership Between Friends. Communication Quarterly 2012; 60:665-680. 